\title{
The Regional Industrial Symbiosis Model for Industrialized Construction Ecosystem
}

\author{
Gui-wen $\mathrm{LIU}^{1}$, Kai-jian $\mathrm{LI}^{2}{ }^{*}$, Yue $\mathrm{TENG}^{3}$ \\ ${ }^{1}$ Professor, Department of Construction Management and Real Estate, Chongqing University, China \\ ${ }^{2}$ PhD candidate, Department of Construction Management and Real Estate, Chongqing University, China \\ likaijian@gmail.com \\ ${ }^{3}$ Senior Researcher, Department of Construction Management and Real Estate, Chongqing University, \\ China
}

\begin{abstract}
Industrialized construction, which utilizes principles associated with factory production, can considerably improve productivity, quality, and service life of building while reduce cost, energy consumption and environmental impact. China government has committed sustainable development and promoted industrialized construction through legislative acts. The number of industrialized public houses in China has rapidly grown to over 3 million per year. However, the ecosystem of industrialized construction of China is still in the infant stage: hesitating stakeholders, sporadic manufacturing, and incomplete industry chain. The aim of this paper is thus to achieve an in-depth understanding of the whole ecosystem of industrialized construction in China. There are four research objectives of this paper: (1) to analyze the symbiotic mechanisms of it based on industrial ecology theory; (2) to build the Regional Industrial Symbiosis (RIS) model of industrialized construction ecosystem based on synergetics theory; (3) to explore the evolutionary trajectories based on the RIS model by simulating the evolutionary trajectory of symbiotic units and analyzing the stable symbiotic point. This paper presented the symbiotic mechanism and four relationships between the populations of industrialized construction ecosystem. It could contribute to the prediction of the evolutionary trajectory of industrialized construction and achieve the policy formulation and implementation.
\end{abstract}

\section{KEYWORDS}

Industrialized construction; ecosystem; industrial symbiosis; synergetics; evolutionary trajectory

\section{INTRODUCTION}

Industrial construction is defined as the manufacture and preassembly of building components, elements, or modular before installation into the final location (Goodier, C and Gibb, 2007). It is an essential mode of construction in most developed countries (Yingbo, J, 2011) and is regarded as an effective method to enhance productivity and alleviate the adverse environmental effects as a result of conventional construction activities (Sev, Am, 2009). In China, industrialized construction has been developed for approximately 20 years. However, the ecosystem of industrialized construction of China is still in the infant stage: hesitating stakeholders (Hui-min, 2008), sporadic manufacturing (Idrus, A and Hui N.F.K, 2008) and incomplete industry chain (Bao-pin and HONG Yin-xing, 2005).

With the promotion of the concept of environmentally friendly, the Bionics theory (Graedel, $\mathrm{T}$. 
E, 1995) has been used in many social activities by different industries. This concept can also be used in the field of construction. There are many stakeholders in industrialized construction and they contact with each other closely through the capital, information or material (Yingbo, J, 2011). The relevance and the degree of dependence will affect the whole system, which is similar to natural ecosystem. As to natural ecosystem which will evolve over time, the members of construction industrialization ecosystem can promote the evolution of the whole system with the characteristic of interconnection and symbiotic coevolution. Research on the evolutionary trajectories in China based on ecological theory is of vital importance as it helps to analyze the developing direction of Industrialized Construction. Synergetics is the science to study the mutual competition and cooperation among each subsystem in the whole system (Haken, $\mathrm{H}$, 1983). It will be used to explain the reason that the whole system covert to the next state.

Therefore, the main aims of this paper is try to analyze the symbiotic mechanisms of industrialized construction ecosystem and build the Regional Industrial Symbiosis (RIS) model based on synergetics theory. Then the evolutionary trajectories of symbiotic units and the stable symbiotic points will be analyzed based on RIS model. This research contributes to predict the future development of industrialized construction in China. It also effectively boosts the evolutionary tempo of the ecosystem as all the participants may do their best to get close to the stable symbiotic points. At the stable stage, the industrialized construction ecosystem can achieve a stable symbiotic state.

\section{MYTHOLOGY}

In the ecosystem, if the effects of the environment and other populations are ignored, the evolution of a single population can be considered to follow the logistic population growth. Logistic equation was put forward by a bio-mathematician whose name is Verhulst (CHEN, Y, 2012). Then it was widely used in the growth or reproduction process of animals or plants. The basic form of the equation is as follow:

$$
\left\{\begin{array}{l}
\frac{d N(t)}{d t}=r\left(1-\frac{N(t)}{K}\right) N(t) \\
N\left(t_{0}\right)=N_{0}
\end{array}\right.
$$

Where $K$ means the carrying capacity (or maximal yield) which describes the maximal capacity under control of the limited resources. $N(t)$ represents the capacity of a population in the industrialized construction symbiotic system. The parameter $r$ means the natural increase intrinsic rate of a population (average increase rate). Such an equation just takes the competition between species within populations. That is to say, with the increase of a species, the inhibiting effect is $1 / K$.

Actually, the industrialized construction ecosystem consists of many populations. The growth of populations is not only influenced by intraspecific competition, but also affected by the ecosystem environment and other populations. The whole system is under a regional industrial symbiotic environment and can achieve co-evolution by the interactions of symbiotic unit. So the Regional Industrial Symbiosis Model will be built based on logistic equation after bringing a symbiotic correlation coefficient.

\section{THE REGIONAL INDUSTRIAL SYMBIOSIS OF INDUSTRIALIZED CONSTRUCTION ECOSYSTEM}

The regional industrial symbiosis of industrialized construction ecosystem can be defined as a 
system which different symbiotic units interact with each other under a certain environment. This symbiotic relationship promotes the industrialized construction ecosystem to improve ecological value within the whole system. So it can generate a synergistic effect. The regional industrial symbiosis of industrialized construction ecosystem is a little different from the natural ecosystem. Some participants communicate and cooperate with each other to lower costs and risks. They evolve together and can be called synergetic symbiosis. This synergy can be seen frequently within industrialized construction ecosystem. Such as the upstream and downstream firms in the industry chain always co-operate fully with each other to achieve a joint development. Some enterprises may build a strategic alliance to reduce the transaction cost. Symbiosis co-evolution is helpful for the units to interact (Sturgeon, T. and Lee, J. R, 2001). If one enterprise receives benefits from the other without damaging it, this can be called commensalism (Jun-cheng, 2010). At the same time, some units also have the characteristics of the competition. This is called competitive symbiosis. Actually, competition will accelerate the speed and the power of evolution in the system. During the competition, some of these companies are eliminated; some are growing to larger companies. There are some units that are independent in the system, which can be called independent symbiosis. The symbiosis mechanism of industrialized construction ecosystem is showed in Table 1.

Table 1. The symbiosis mechanism of industrialized construction ecosystem

\begin{tabular}{|c|c|}
\hline $\begin{array}{l}\text { Symbiotic } \\
\text { relationship }\end{array}$ & The symbiosis mechanism of industrialized construction ecosystem \\
\hline $\begin{array}{l}\text { Synergetic } \\
\text { symbiosis }\end{array}$ & $\begin{array}{l}\text { (1) The upstream and downstream firms in the industry chain. For example: } \\
\text { Raw material suppliers and suppliers of finishing material; Suppliers of } \\
\text { electrical equipment and construction units } \\
\text { (2) Some strategic alliance } \\
\text { (3) The others: Realestate developers and Suppliers of components; the } \\
\text { construction units and designers. }\end{array}$ \\
\hline Commensalism & Government, intermediary service institutions and other industries. \\
\hline $\begin{array}{l}\text { Competitive } \\
\text { symbiosis }\end{array}$ & $\begin{array}{l}\text { (1)Suppliers of finishing material, Suppliers of construction material, Suppliers } \\
\text { of special material demand for the same raw materials } \\
\text { (2)Real estate developers have their own research institutions, property } \\
\text { management companies and sales agent institutions which may compete with } \\
\text { the others } \\
\text { (3)Some construction units or real estate developers have the design } \\
\text { qualification, so there will be a competition between them and the designers. }\end{array}$ \\
\hline $\begin{array}{l}\text { Independent } \\
\text { symbiosis }\end{array}$ & $\begin{array}{l}\text { Without direct business connection between the populations: The relationship } \\
\text { between Research institutions, Property management company, Cost } \\
\text { consultancy, designer, Financing institution and Sales agent institution }\end{array}$ \\
\hline
\end{tabular}

\section{THE RIS MODEL OF INDUSTRIALIZED CONSTRUCTION ECOSYSTEMBASED ON SYNERGETICS}

Synergetics, created by Harmann-Haken(1984), is a combination of natural science and social science. Synergetics theory is about how the multicomponent system achieves the evolution by subsystem's coordinated actions. So the ecosystem can be self-organized can achieve independent evolution from disordered to ordered circumstance. In nature, an ecosystem must experience the development process from to infant stage to mature period (Zhao, J and LIU, Y. $\mathrm{P}, 2010)$. This is known as the evolution of the system. Evolution and co-evolution is a common 
phenomenon in nature. The theory comes from the natural science and later is widely used in the research of abiotic field, such as geology, astronomy, economics and management science, etc. Futuyama and Slatkin put forward the co-evolution was an adaptive feedback of one species to the changes of other species. It was mutualistic evolution between all the species (Porter, M. E and Kramer, M. R, 2006). Jouhtio(2006) pointed out co-evolution was a continuous change that occurred in two or more interdependent species. They adapted to each other and have intertwined evolution trajectories. Such a view makes a difference between the co-evolution theory and the general evolution theory: co-evolution theory emphasizes the interaction between species, while the general evolution theory believes that the process of species' evolution is isolated from the effect of related species and environment (Nelson, R. R, 1994). All the changes of them will not be taken into account.

Therefore, the co-evolution of RIS model of industrialized construction ecosystem is caused by the interaction of all the populations. By establishing the model of evolution based on synergetics, it is beneficial to analyze the development direction of industrialization construction. Also it is helpful to explore the sable point of the system, which is indeed help to boost the industrialization construction in China.

The Regional Industrial Symbiosis (RIS) model of industrialized construction ecosystem According to the methodology, the RIS mode can be expressed based on the formula (1) after bringing a symbiotic correlation coefficient. Suppose there are only two populations in the ecosystem, for population 1 , as it is influence by population, the RIS mode of population 1 is as follow:

$$
\frac{d N_{1}}{d t}=f_{1}\left(N_{1}, N_{2}\right)=r_{1}\left(1-\frac{N_{1}}{K_{1}}-\frac{b_{1} N_{2}}{K_{1}}\right) N_{1}
$$

Where $b_{1}$ means the symbiotic correlation coefficient of population 2 to 1 . The absolute value of $b_{1}$ represents the strength of the symbiosis.

Similarly, the RIS mode of population $l$ can be expressed as follow:

$$
\frac{d N_{2}}{d t}=f_{2}\left(N_{1}, N_{2}\right)=r_{2}\left(1-\frac{N_{2}}{K_{2}}-\frac{b_{2} N_{1}}{K_{2}}\right) N_{2}
$$

For the industrialized construction ecosystem, the symbiotic relationship can be analyzed below in Table 3.

Table 3. The symbiotic relationship analys is of industrialized construction ecosystem

\begin{tabular}{ccl}
\hline Relationship & $\begin{array}{c}\text { Symbiotic correlation } \\
\text { coefficient }\end{array}$ & \multicolumn{1}{c}{ Descriptions } \\
\hline Synergetic symbiosis & $b_{1}<0, b_{2}<0$ & $\begin{array}{l}\text { Benefit for both populations. If b1=b2, it means the } \\
\text { relationship is mutualism } \\
\text { Compete with each other and achieve the co- } \\
\text { evolution during the process. }\end{array}$ \\
Competitive symbiosis & $b_{1}>0, b_{2}>0$ & $\begin{array}{l}\text { Benefit for the population which } b<0 ; \\
\text { Do not have effect on the population which } b=0 . \\
\text { Mutual independence; } \\
\text { Evolution by themselves to boost the whole } \\
\text { system. }\end{array}$ \\
\hline$b_{1}=0, b_{2}<0$ or $b_{1}<0, b_{2}=0, b_{2}=0$ & $b_{1}$ & andependent symbiosis
\end{tabular}

As the industrialized construction ecosystem are consists of many populations, so it can be explained in a general RIS mode. When there exists " $n$ " populations, the RIS mode of symbiotic unit " $i$ " can be expressed as follow: 


$$
\left\{\begin{array}{l}
\frac{d N_{1}}{d t}=r_{1}\left(1-\frac{N_{1}}{K_{1}}-\sum_{j=2}^{n} \frac{b_{1 j} N_{j}}{K_{j}}\right) N_{1} \quad i=1 \\
\frac{d N_{i}}{d t}=r_{i}\left(1-\frac{N_{i}}{K_{i}}-\sum_{j=1}^{i-1} \frac{b_{i j} N_{j}}{K_{j}}-\sum_{i=1}^{n} \frac{b_{i j} N_{j}}{K_{j}}\right) N_{i} \quad n \geq i \geq 2
\end{array}\right.
$$

Where parameter $K_{i}$ means the largest potential scale of symbiotic unit " $i$ ". $N i$ can be explained the scale of symbiotic unit " $i$ " now. Where $K j$ means the largest potential scales of the symbiotic unit $j$. " $j$ " is one of other symbiotic units except " $i$ ". $N j$ can be explained the scale of symbiotic unit " $j$ " now. All the symbiotic units will follow formula (4) and promote the evolution of the whole ecosystem together.

\section{THE EVOLUTIONARY TRAJECTORIES BASED ON RIS}

Suppose there are two populations in industrialized construction ecosystem. We can research the evolutionary trajectories of the two units based on the RIS model. Then it can be applied to general situation. Usually, parameter $b_{1}$ is independent of $b_{2}$. Suppose $f_{1}\left(N_{1}, N_{2}\right)=0$, $f_{2}\left(N_{1}, N_{2}\right)=0$. So the steady-state solution (Gardner, W. R, 1958) of the formula can be obtained: $A(0,0) ; B\left(0, K_{2}\right) ; C\left(K_{1}, 0\right) ; D\left(\frac{K_{1}\left(1-b_{1}\right)}{1-b_{1} b_{2}}, \frac{K_{2}\left(1-b_{2}\right)}{1-b_{1} b_{2}}\right)$.According to the differential geometry theory

(Kobayashi, S, 1963), the isoclinic lines can be presented as follow:

$$
\begin{aligned}
& 1-\frac{N_{1}}{K_{1}}-\frac{b_{1} N_{2}}{K_{1}}=0 \\
& 1-\frac{N_{2}}{K_{2}}-\frac{b_{2} N_{1}}{K_{2}}=0
\end{aligned}
$$

To population 1: $N_{1}=0, N_{2}=K_{1} / b_{1} ;$ if $N_{2}=0, N_{1}=K_{1}$

To population 2: $N_{1}=0, N_{2}=K_{2} ; N_{2}=0, N_{1}=K_{2} / b_{2}$

The difference of $K_{1}, K_{2}, b_{1}, b_{2}$ also brings various growing balance lines. So we can explore the evolutionary trajectories of symbiotic units based on RIS model under the four symbiotic relationships.

The evolutionary trajectories of units in the relationship of synergetic symbiosis In this condition, $b_{1}<0, b_{2}<0$. The growing balance lines can be analyzed below:

- When $\left|K_{1} / b_{1}\right|>K_{1}$ and $\left|K_{2} / b_{2}\right|>K_{2}$, this is $\left|b_{1} b_{2}\right|<1$, the evolutionary trajectories of symbiotic units are shown in figure 1 . We can get four steady-state solutions: $A_{1}(0,0) ; B_{1}\left(0, K_{2}\right) ; C_{1}\left(K_{1}, 0\right) ; D_{1}\left(\frac{K_{1}\left(1-b_{1}\right)}{1-b_{1} b_{2}}, \frac{K_{2}\left(1-b_{2}\right)}{1-b_{1} b_{2}}\right)$. It can be seen $D_{1}$ located in the stable sate after the growth of two populations. So the stable solution is $D_{1}\left(\frac{K_{1}\left(1-b_{1}\right)}{1-b_{1} b_{2}}, \frac{K_{2}\left(1-b_{2}\right)}{1-b_{1} b_{2}}\right)$.

- When $\left|b_{1} b_{2}\right| \geq 1$, the evolutionary trajectories of symbiotic units can be shown in figure 2 . There are only three steady-state solutions: $A(0,0) ; B\left(0, K_{2}\right) ; C\left(K_{1}, 0\right)$. The stable solution is not existence so it cannot achieve a stable symbiotic state.

The two populations can strengthen symbiotic effect after cooperating and communicating with each other on technology, management and capital. The co-evolution of two boosts the development of industrialized construction ecosystem so that it helps to reach the stable state. 


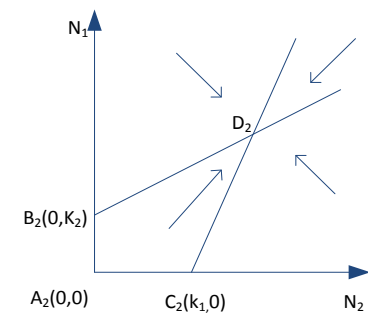

Figure 1

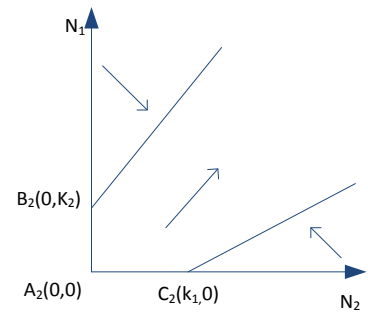

Figure 2

The evolutionary trajectories of units in the relationship of competitive symbiosis

In this condition, $b_{1}>0, b_{2}>0$. And there are four evolutionary trajectories of symbiotic units:

- When $K_{1}>K_{2} / b_{2}, K_{2}<K_{1} / b_{1}$, the capacity of population 1 is larger than populaiton2. And between the two lines population 1 can grows continually, while unit 2 has reached its maximum capacity. At last, the winner is population 1. It can be seen in figure 3 .

- When $K_{1}<K_{2} / b_{2}, K_{2}>K_{1} / b_{1}$, the situation is in contrast to the (1). So the winner is population 2 and this can be seen in figure 4 .

- When $K_{1}<K_{2} / b_{2}, K_{2}<K_{1} / b_{1}$, two growing balance lines meet in the point $D_{2}$. In the area of $D_{2}, B, K_{1} / b_{1}$, population 2 cannot grow continually, while population 1 gradually increase and have a tendency to reach its stable point. In the area of $D_{2}, C, K_{2} / b_{2}$, population $l$ cannot grow continually, while population 2 gradually increase and have a tendency to reach its stable point. The two units meet at point $D_{2}$ to achieve a stable state. The process can be express in figure 5 .

- When $K_{1}>K_{2} / b_{2}, K_{2}>K_{1} / b_{1}$, two growing balance lines meet in the point $D_{2}$. The growing direction is contrary to that in (3). Population 1 has the tendency to point $C$ while 2 grows to point $B$. But the two cannot achieve a stable balance state. They are in unstable competition situation and the winner is unknown. That can be seen in figure 6 .

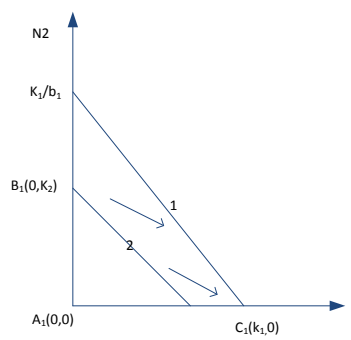

Figure 3

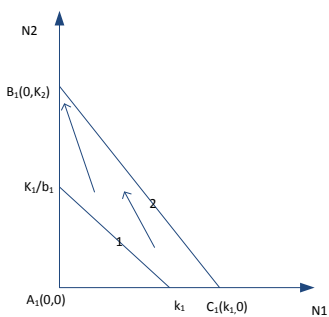

Figure 4

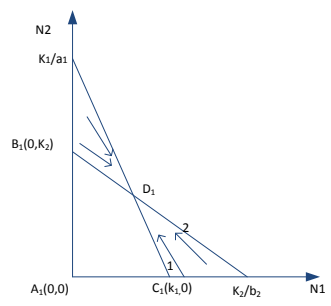

Figure 5

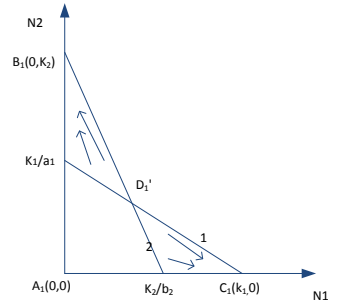

Figure 6

The evolutionary trajectories of units in the relationship of commensalism

In this condition, $b_{1}=0, b_{2}<0$ or $b_{1}<0, b_{2}=0$. There are two evolutionary trajectories of symbiotic units:

- When $b_{1}=0, b_{2}<0$, the growing balance line of population $l$ is a vertical line which crosses the point $C\left(K_{1}, 0\right)$. The growing balance line of population 2 which cross $B$ meet it at $D_{3}$. Both of them see a gradually increase and reach their own steady-state solutions. The point $D_{3}$ is the stable point. This can be seen in figure 7 .

- When $b_{1}<0, b_{2}=0$, the growing balance line of population 1 is a horizontal line which crosses the point $B\left(0, K_{2}\right)$. Similarly, the two see a stable point at $D_{3}$. This can be expressed in figure 8 .

The evolutionary trajectories of units in the relationship of independent symbiosis

When $b_{1}=0, b_{2}=0$, growing balance line of population $l$ is $N_{1}=K_{1}$. And $N_{2}=K_{2}$ is for population 2. Therefore the evolutionary trajectories can be expressed in figure 9. In the situation of independent symbiosis, two populations will reach to its own steady-state point. At last they 
will meet at one point that both of them can survive. Such a situation is a stable state.

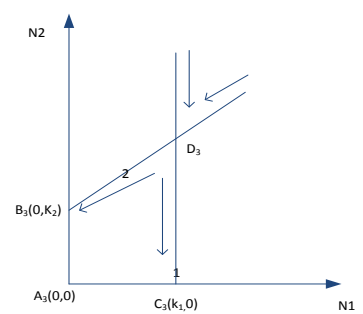

Figure 7

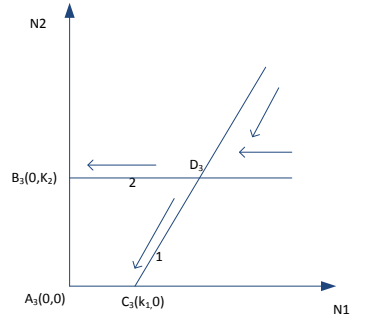

Figure 8

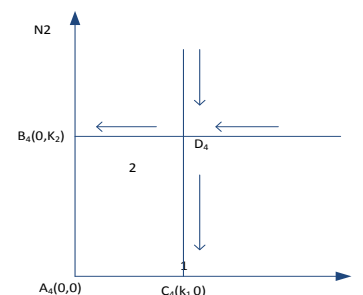

Figure 9

\section{DISCUSSION}

Due to the ecological characteristics of industrialized construction, it is feasible to introduce the ecology theory to the research of it. So the symbiotic mechanism of the industrialized construction ecosystem was built to present the relationship between all the populations. There are four symbiotic relationships between populations in industrialized construction ecosystem: synergetic symbiosis, competitive symbiosis, commensalism and independent symbiosis. All the populations are classified to these four categories. But it is in an initial state and every units and participates are unstable because all of them will increase and become larger. The ecosystem consists of many populations, so they are not only affected by the inner factors, but also influenced by other populations. Therefore, the RIS mode was used to analyze the evolutionary trajectories of symbiotic units in the whole system. Such a mode is based on "logistic" but brings symbiotic correlation coefficient to make it more reliable.

According to synergetics, the subsystem can reach some critical points due to the nonlinear cooperative and coherent effects. It can generate a new system based on fluctuation, which is quite different from the primary one. That is to say, if we want to explore a stable state, we need to accelerate the interaction between subsystems on one hand and ensure the stable solution on other hand. Synergetics helps to solve the first problem and by using RIS mode, we analyzed the stable solution and got reach at a stable symbiotic state. As there are four relationships between the symbiotic units, for each one there will be a stable solution. On that state the whole system will convert to the last stage. Such an evolutionary trajectory follows the evolution of natural ecosystem. The whole system will constantly change until it achieves the last stable state.

\section{CONCLUSION}

This paper depicted an overview of industrialized construction ecosystem. Then it presents the symbiotic mechanism and put forward there are four relationships between the populations of industrialized construction ecosystem. The RIS mode has been built to analyze the evolutio nary trajectories of industrialized construction ecosystem. For different relationships, there are various evolutionary trajectories and stable state. The RIS mode reflects the evolution of the whole system, which is similar to the natural ecosystem. They will change from time to time until it reaches at the stable state. This research is quite useful for the development of the whole industrialized construction in China. It is still in infant stage and the evolution is indispensable. So the stable state can be seen as the objects of our development. What's more, for different relationships there are different development paths. According to the introduction of data from different periods, we can analyze if the relationship between two populations has changed by calculating the symbiotic correlation coefficient. This will help to adjust strategies for participates which can promote the evolution of the industrialized construction. 


\section{ACKNOWLEDGMENT}

The author gratefully acknowledges the support of K.C. Wong Education Foundation, Hong Kong. This study was also financially supported by the Fundamental Research Funds for the Central Universities in China (No.106112014CDJSK030002) and Chongqing Graduate Student Research Innovation Project (No.CYS14036).

\section{REFERENCES}

Bao-pin, HONG Yin-xing (2005). An Approach of Improvement of the Economic Effectiveness in New-type Industrialization: Analysis of the Visual Angle of a Kind of Industry Chain [J]. Journal of Northwest University.

CHEN, Y., \& XIE, F. J. (2012). The Bionics Research of Evolutionary Path of Photovolta ic Industry's Innovation Ecosystem Based on Lotka Volterra Model [J]. R\&D Management, 3, 007.

Gardner, W. R. (1958). Some steady-state solutions of the unsaturated moisture flow equation with application to evaporation from a water table. Soil science, 85(4), 228-232.

Goodier, C., \& Gibb, A. (2007). Future opportunities for offsite in the UK. Construction Management and Economics,25(6), 585-595.

Graedel, T. E., Allenby, B. R., \& COMRIE, P. (1995). Matrix approaches to abridged life cycle assessment. Environmental Science \& Technology, 29(3), 134A-139A.

Haken, H. (1983). Synergetics. Edited by Peter Fulde, 341.

Herre, E. A., Knowlton, N., Mueller, U. G., (1999). The evolution of mutualisms: exploring the paths between conflict and cooperation. Trends in Ecology \& Evolution, 14(2), 49-53.

Hui-min, Q. Z. F. L. (2008). Thinking of the Development of the Industrialization of Our Construction Industry. Jiangsu Construction, S1.

Idrus, A., \& Hui, N. F. K. (2008). Perception of Industrialized Building System (IBS) Within the Malaysian Market.

Jouhtio, M. (2006). Co-evolution of industry and its institutional environment. The Institute of Strategy and International Business in Helsinki University of Technology.

Jun-cheng, Z. H. U. (2010). Research of Regional Polycentric Coordinated Development Based on Symbiosis Theory [J]. Economic Geography, 8, 007.

Kobayashi, S. (1963). K. NOMIZU Foundations of differential Geometry. Interscience, New York London.

Nelson, R. R. (1994). The co-evolution of technology, industrial structure, and supporting institutions. Industrial and corporate change, 3(1), 47-63.

Porter, M. E., \& Kramer, M. R. (2006). The link between competitive advantage and corporate social responsibility. Harvard business review, 84(12), 78-92.

Sev, A. (2009). How can the construction industry contribute to sustainable development? A conceptual framework. Sustainable Development, 17(3), 161-173.

Sturgeon, T., \& Lee, J. R. (2001, June). Industry co-evolution and the rise of a shared supply-base for electronics manufacturing. In Nelson and Winter Conference, Aalborg, June.

Yingbo, J. (2011). The Development of Industrial Housing Construction in Singapore as a Reference for China. Reformation \& Strategy, 7, 060.

Zhao, J., \& LIU, Y. P. (2010). The Co-evolution of Industrial Cluster Ecosystem based on Loop Analysis [J]. Scientific Management Research, 2, 017. 